\title{
Representaciones de mujeres criminales través del Anuario Estadístico en el Departamento de Bolívar, Colombia $\left(1950\right.$ - 1960) ${ }^{1}$
}

\author{
Representations of women criminals through the Statistical Yearbook \\ in the Department of Bolivar, Colombia (1950 - 1960)
}

Representações de mulheres criminosas através do Anuário Estatístico no Departamento de Bolívar, Colômbia (1950 - 1960)

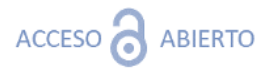

Para citaciones: Castrillón, C. (2021). Representaciones de mujeres criminales través del Anuario Estadístico en el Departamento de Bolívar, Colombia (1950 - 1960). El Taller de la Historia, 13(1), 233-250.

Recibido: marzo de 2021

Aprobado: mayo de 2021

Editor: Sergio Paolo Solano. Universidad de Cartagena-Colombia.
Copyright: (C 2021. Castrillón, C. Este es un artículo de acceso abierto, distribuido bajo los términos de la licencia https://creativecommons.org/licenses/by-ncsa/4.0/ la cual permite el uso sin restricciones, distribución y reproducción en cualquier medio, siempre y cuando que el original, el autor y la fuente sean acreditados.

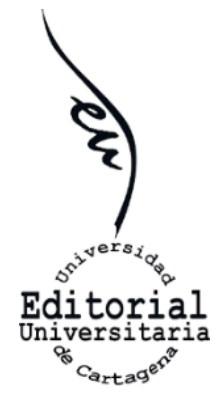

Carlos Mario Castrillón Castro ${ }^{2}$ iD

Universidad Iberoamericana, CDMX

\begin{abstract}
RESUMEN
El presente trabajo tiene como finalidad explorar representaciones de criminalidad a través del Anuario Estadístico, sección Criminalidad y Justicia, del cual se obtienen un conjunto de datos relacionados con la construcción sistema criminal. Esta revisión permite abordar la manera en cómo se cuantificó a unos personajes, practicas y conductas que influyeron en la concepción de unas mujeres representadas como criminales. Se trata de identificar las principales ideas, interpretaciones, normas y comportamientos en los modos de registrar y documentar la vida de las mujeres asociadas a la criminalidad aterrizado a el Departamento de Bolívar.
\end{abstract}

Palabras clave: mujeres criminales; transgresoras; estadísticas; representaciones.

\begin{abstract}
This paper aims to explore representations of criminality through the Statistical Yearbook, section Criminality and Justice, which obtains a set of data related to the construction criminal system. This review allows us to address the way in which characters, practices and behaviors that influenced the conception of women represented as criminals were quantified. It is about identifying the main ideas, interpretations, norms and behaviors in the ways of recording and documenting the lives of women associated with the criminality landed in the Department of Bolívar.
\end{abstract}

Keywords: criminal women; transgressors; statistics; representations.

\footnotetext{
${ }^{1}$ Este artículo fue producto del proyecto "Transgresión y delitos de las mujeres en sectores populares de Cartagena: estadísticas, discursos y control en la década del 50 del siglo XX” investigación financiada por la Universidad Andina Simón Bolívar sede Ecuador en su estimulo de Becas de Investigación en el año 2018.

${ }^{2}$ Magister en Estudios de la Cultura , con mención en Género y Cultura, Universidad Andina Simón Bolívar Ecuador. Doctorante Estudios Críticos de Género, en la Universidad Iberoamericana, CDMX. krlos.m@hotmail.com
} 


\section{RESUMO}

Este artigo tem como objetivo explorar representações de criminalidade por meio do Anuário Estatístico, seção Crime e Justiça, que obtém um conjunto de dados relacionados ao sistema penal de construção. Esta revisão permite abordar a forma como personagens, práticas e comportamentos que influenciaram a concepção das mulheres representadas como criminosas foram quantificados. Trata-se de identificar as principais ideias, interpretações, normas e comportamentos nas formas de registrar e documentar a vida das mulheres associadas à criminalidade desembarcada no Departamento de Bolívar.

Palavras-chave: mulheres criminosas; transgressoras; estatísticas; representações.

\section{Introducción}

Hacia 1940, en la historia de la estadística de Colombia hubo lugar para una discusión referente a la criminalidad en el país y este debate, a su vez, se vio influido por el Acuerdo No.418 de 1937 donde se reglamenta la estadística sobre criminalidad, justicia y movimiento carcelario. Un campo que generó debate a nivel nacional derivándose algunos ejes temáticos tales como lo fueron; la seguridad social, su implicación al afectar un bien público y jurídico protegido por el Estado. ${ }^{3}$ Además, este documento perfiló las características de los hombres y mujeres delincuentes a partir de los dieciocho años. ${ }^{4}$

Es en esta coyuntura es donde se presenta un ensayo de interpretación estadística, ${ }^{5}$ donde se analizan las características personales de los delincuentes, los delitos, según sean, en conjugación con los registros sociales y económicos. Paralelamente, desde 1938, en el censo de población y los anuarios estadísticos comenzó a aparecer un capítulo dedicado a la criminalidad y justicia. ${ }^{6}$ Por un lado, se puede extraer información que provienen de diversas dimensiones de la realidad social como el analfabetismo, salario, higiene, entre otras, pero también, contienen indicadores como el sexo, la edad, el estado civil, el lugar de procedencia y los oficios. Su propósito es mostrar un panorama general de algunas situaciones que pudieron estar sujetas a las personas y su pasado criminal, aunque los datos señalados, a su vez, permiten explorar la construcción de una representación que sirvió como fundamento para justificar problemas sociales.

Tales cuantificaciones eran hechas y suministradas por fuentes informativas como; Alcaldías Municipales, Inspecciones de Policía, Juzgados Penales y

\footnotetext{
${ }^{3}$ Luis Vidales, Historia de la estadística en Colombia, Bogotá, Banco de la Republica/Departamento Administrativo Nacional de Estadística, 1978.

${ }^{4}$ Los datos de delincuencia infantil y justicia de menores no se encuentran incorporados en este estudio.

${ }^{5}$ L. Vidales, "Un ensayo sobre criminalidad en el país", en Historia de la estadística en Colombia, Bogotá, Banco de la Republica/Departamento Administrativo Nacional de Estadística, 1978.

${ }^{6}$ Anuario general estadístico, Bogotá, Departamento Administrativo Nacional de Estadística, 1960) 361.
} 
Promiscuos Municipales, de Instrucción Criminal y de Policía. ${ }^{7}$ Instituciones con valores tradicionales quienes utilizan el poder de recolección y análisis de datos para suministrar información y construcción de un documento, el cual, expone y categoriza a la población criminal en tablas numéricas. Las estadísticas difundidas permitieron legitimar denuncias que se realizaban de manera cotidiana en los periódicos (locales y nacionales) por parte de autoridades administrativas y la ciudadanía en general. ${ }^{8}$

Ahora bien, para esta investigación se utilizó como fuente el Anuario Estadístico de 1950 hasta 1960, publicación que documentó "experiencias" en un periodo que construyó un sistema de signos que expresó y difundió denuncias a causa de "la inseguridad" y "los crímenes". Con la interpretación de los datos estadísticos es posible reconstruir ¿Qué se dice?, ¿Qué se aborda?, ¿Cuáles son las principales características del crimen? Nos ocuparemos de las mujeres al ser tenidas en cuenta como personajes protagónicos que tienen participación y presencia en una visión de mundo que legitima y busca dar orden a la sociedad.

A todo esto, valdría la pena preguntarse ¿Qué representación generan las estadísticas?, al interesarnos en trabajar con el Anuario Estadístico lo que se busca es mostrar una visión construida, basada en organizar el entendimiento de unos comportamientos, como la criminalidad. Los números reflejan procesos, estructuras sociales e imágenes o como lo plantea la historiadora Joan Scott "nos aportan ideas muy valiosas sobre los procesos por los cuales las relaciones de poder se establecen, se ejemplifican, son impugnadas y acaban por imponerse". ${ }^{9}$ Es decir, se estudian concepciones dominantes y practicas de recolección de información relacionadas con el comportamiento en las que se coloca dicotomías que organizan el entendimiento y el conocimiento.

Por tal motivo, el Anuario Estadístico será estudiado desde una perspectiva de género al permitirnos ubicar a las mujeres y hombres en circunstancias de producción y reproducción de un sistema criminal. Fue un espacio para contabilizar características que definen a las mujeres y a los hombres de manera especifica, así como sus semejanzas y diferencias. Se trata de ver los símbolos y los atributos asignados a las personas en las que podemos encontrar características sociales, judiciales, culturales, entre otras, que dan significado y lugar en el mundo.

En consecuencia, el Anuario Estadístico y su sección Criminalidad y Justicia serán vistos como un documento que presenta información que da sentido al

\footnotetext{
7 "Estadísticas de criminalidad y justicia". Anuario general estadístico, Bogotá, Departamento Administrativo Nacional de Estadística, 1960, p. 361.

${ }^{8}$ Carlos Mario Castrillón Castro y Lizett Paola López Bajo, “Al límite de la violencia de género: representaciones de transgresiones protagonizadas por mujeres en la prensa cartagenera, 1940-1950”. La Manzana de la Discordia, 11, (1), 2016: 29-39

9 Joan W Scott, "El género: una categoría útil para el análisis histórico" en James S. Amelang y Mary Nash (eds.), Historia y género: las mujeres en la Europa moderna y contemporánea, Madrid, Edícions Alfons el Magnanim, 1990, pp. 23-58.
} 
mundo criminal mediante la construcción de un sistema escrito en el que se describen personas, sexo, edades, oficios, caracteristicas, eventos, normas, leyes, e ideas.

La finalidad de toda la información recolectada es que funcione como signo dentro de un sistema en el cual desde la cuantificación se haga visible un significado y que pueda ser desifrable tal y como se presenta. Es así como las estadisticas serán utilizadas como una representación desde el como exiben presencia publica de unas experiencias o personas y se convierten en un instrumento de conocimiento que permite ver un acontecimiento ${ }^{10}$.

\section{Criminalidad en Colombia}

Los datos estadísticos sobre criminalidad [...], dan base para una ponderación con las circunstancias sociales del país, de indudable utilidad para apreciar y estudiar los factores influyentes... ${ }^{11}$

Gracias a la construcción hecha por las distintas instituciones que contribuyeron a dar información para que los Anuarios Estadísticos y el Censo Nacional pudieran reconstruir y exhibir a partir de instrumento que representó las experiencias delincuenciales.

Gracias a dicha presentación pública se puede ver hacer una identificación del crimen por años de la siguiente forma; para el periodo de 1940, un 0,48\% de la población total de Colombia, donde los hombres conformaron el grupo más numeroso con un 89,23\%, mientras que las mujeres representan 10,29\%; para 1951 , un $0,65 \%$ de la población total de Colombia, conformado por un $83,20 \%$ para hombres y un 7,58\% de mujeres; por último, tenemos que para 1960 el porcentaje es de un 1,05\% de la población total de Colombia, integrado por un $93,48 \%$ de hombres y el $6,53 \%$ de mujeres.

La puesta en escena de las cifras registradas por parte de los Anuarios Estadísticos muestran concepciones de mundo relacionadas con la construcción de un conjunto o una cadena de equivalencias en relación a la inseguridad social el cual se hace visible al exponer unos registros de población criminal.

Los datos constituyen una forma de acercarnos a las representaciones del comportamiento criminal se ubican mujeres y hombres definidos por su forma de participación en un espacio y contexto social, es un conjunto de experiencias reunidas en tres décadas en la que se ubica un porcentaje de 3,5\% de crímenes en relación a otras actividades. La siguiente tabla nos dará una relación de las estadísticas señaladas:

\footnotetext{
${ }^{10}$ Roger Chartier, "El mundo como representación", en El mundo como representación. Historia cultural: entre practica y representación, Madrid, Editorial Gedisa, 1992, p. 57

${ }^{11}$ Juan María Aguilar, La criminalidad en el Departamento de Santander - apuntes para un estudio sociológico.
} 
Tabla 1: Número de sindicados en los sumarios iniciados en el país

\begin{tabular}{|r|r|r|r|}
\hline Años & \multicolumn{1}{c|}{ Sumarios } & Hombres & \multicolumn{1}{c|}{ Mujeres } \\
\hline \multicolumn{4}{|c|}{ Sumarios iniciados en el país } \\
\hline 1940 & 41.848 & 37.341 & 4.307 \\
\hline 1951 & 72.787 & 60.559 & 5.520 \\
\hline 1960 & 147.854 & 138.208 & 9.648 \\
\hline
\end{tabular}

Fuente: Anuario General de Estadística, Bogotá, DANE, 1940-1960

Dichas cifras son elementos fundamentales para el conocimiento histórico al representar tendencias del comportamiento criminal a nivel nacional, pero a su vez, habría que interrogar a esta información ¿cuál es la necesidad al construir los datos?, ¿qué aportes están generando las cifras?, ¿con que finalidad fueron difundidos? A esto, se podría decir que, la construcción del Anuarios Estadístico permitió la gestión administrativa sobre conductas perfiladas una mirada de control sobre el desarrollo de la criminalidad. También, permite reconocer que, la administración de justicia se encontraba en función creciente ya que, tanto hombres como mujeres se convirtieron en personajes relacionales y produjeron un discurso filtrado sobre el crimen.

Si bien se expone una clara división sexual en las estadísticas de criminalidad que permite el análisis de una sociedad la cual se enfrenta algunas coyunturas marcadas por su condición de género. En términos generales, se podría decir que de la información recolectada sobre la criminalidad en Colombia representa unas coyunturas vividas en la mitad del siglo XX. Muestra unas experiencias mediadas o relacionadas, en gran parte, por los rezagos de la violencia política y que se intensificó una vez fue electo e inició su administración el presidente Laureano Gómez, para el periodo de 1950 hasta $1953 .{ }^{12}$

De esta manera entramos a los inicios de los años 50 del siglo $\mathrm{XX}$, donde la historiografía ha descrito enfrentamientos políticos en las regiones del país, se dice que, solamente para las planicies costeras del norte colombiano los efectos fueron menores y donde hubo mayor manifestación fue en los sectores rurales y no urbano. Generalmente la violencia generó enfrentamientos entre campesinos de un partido contra campesinos de otro partido y a esta coyuntura de sangre y actos violentos se le atribuye como consecuencia el "bandidaje" llevado a cabo por delincuentes profesionales o por liberales y conservadores que habían sido expulsados de sus fincas por adherentes del partido contrario y adoptaron una vida criminal como la manera más práctica de supervivencia en las circunstancias del país. ${ }^{13}$

Otro factor influyente a tener en cuenta en crecimiento de las cifras delincuenciales está relacionada con los cambios significativos, en gran medida, causados por "la duplicación de la población urbana y los intensos

${ }^{12}$ David Bushnell, Colombia. Una nación a pesar de sí misma. De los tiempos precolombinos a nuestros días, Bogotá, Ed. Planeta, 1994, p. 282.

${ }^{13}$ D. Bushnell, Colombia. Una nación a pesar de sí misma, pp. 282-283. 
procesos de urbanización que se dio en las décadas del cuarenta, cincuenta y sesenta". ${ }^{14}$ Según quedó registrado en los censos de 1951 a 1964, la tasa anual de crecimiento en el país se presenta como una consecuencia del descenso de los niveles de mortalidad, estimulados por las políticas higienistas. ${ }^{15}$ Todos estos cambios tomaron por sorpresa al país y generaron desproporciones en la administración ${ }^{16}$ además de nuevos temores convirtiendo el discurso de la seguridad en una de las principales preocupaciones y discusiones como parte de las medidas gubernamentales.

Se podría resumir el contexto histórico y político de las estadísticas de Criminalidad y Justicia en dos situaciones, por un lado, la violencia política y por el otro el crecimiento de la población urbana en los años 50 provocó dificultades sociales. Estas fueron desde los enfrentamientos políticos, los desplazamientos locales y los problemas económicos que experimentó el país, al estar enfrentando una situación de pobreza y falta de oportunidades. ${ }^{17}$ Lo expuesto hasta aquí puede ser uno de los motivos por los cuales se evidencian aumentos en las cifras, referencias que pueden ser vistas como las principales causas que llevaron a hombres y mujeres a incursionar en la criminalidad y la delincuencia.

Para la década de estudio (1950 - 1960), se encontraron registros o denuncias en la prensa, en relación a la inseguridad urbana. La delincuencia se convirtió en parte de la cotidianidad y, por ello, se la debatió fuertemente. Denuncias, quejas ciudadanas o discursos sobre robos en los establecimientos comerciales, la vigilancia y el accionar de la policía ${ }^{18}$, lo anterior desencadenó una circulación y producción de noticias relacionadas con este tema. ${ }^{19}$

Es así como la noticia del 03 de septiembre de 1941, descrita por el periódico El Fígaro de Cartagena, llamó la atención de sus lectores al colocar en el debate público las cifras de "criminalidad y delincuencia en Colombia". La noticia, hace un llamado de atención desde dos aspectos, por un lado, a las autoridades y a la ciudadanía en general alertando sobre una problemática que expuso experiencias de inseguridad a nivel nacional con hechos y cifras. Por el otro, "hizo elogio de la mujer colombiana", narrativa que expuso una participación de un $87 \%$ de hombres y un $13 \%$ de mujeres, ${ }^{20}$ el cual colocó en evidencia la obstinación, por parte de la noticia, en relación a la

\footnotetext{
${ }^{14}$ Hasta el censo de 1938 solo cuatro centros o ciudades superaban el número de 1000 habitantes, de 1951 a 1964 se elevaron las cifras, lo cual implico un nivel de desarrollo. Véase: Asociación Colombiana para Estudio de la Población (ACEP), La Población de Colombia, Bogotá, C.I.C.R.E.D. series, 1974, p. 43.

${ }^{15}$ Gracias al avance acelerado de la medicina, la mortalidad se fue reduciendo notablemente, más no en igual forma la fecundidad, originando tasas elevadas de crecimiento. Tomado de: ACEP, La Población de Colombia, p. 32 . Tambien Véase: Álvaro Casas León Orrego, Higienizar, medicar, gobernar. Historia, sociedad y salud en Colombia, Medellín, GIHSA, Universidad Nacional de Colombia sede Medellín, 2004.

${ }^{16}$ Uno de los factores que priman en este periodo es el incremento poblacional hecho que tomó por sorpresa al país y debido a la imprevisión se originó una desproporción entre los recursos y las necesidades vitales de sus habitantes. ACEP, La Población de Colombia, p. 32

${ }^{17}$ D. Bushnell, Colombia. Una nación a pesar de símisma, p. 285.

18 "Diversos establecimientos comerciales bajo la acción de los cacos; desmantelada una vitrina" El Universal, Cartagena, abril 5, 1955

19 "El problema de las Cárceles", El Universal, Cartagena, noviembre 6, 1959

20 "El censo de presos en Colombia”, El Fígaro, Cartagena, septiembre 3, 1941
} 
incertidumbre que generó un planteamiento más amplio y es el de determinar la condición de cualquier mujer que viva fuera de los contextos habituales de la familia.

Hablar de mujeres criminales implicaba "desorden", "amenaza" irregularidad y corrupción. Exponer experiencias de mujeres criminales en los registros estadísticos reflejaba un comportamiento que amenazaba el orden moral, e implicaba problemas en la representación de la familia. Las mujeres sindicadas y condenadas fueron una codificación representada en la preocupación por el descontrol, la corrupción, la no regulación, la construcción de la siguiente tabla puede ser una muestra

Tabla 2: Delitos de las mujeres sindicadas y condenadas en Colombia entre 1951 - 1960

\begin{tabular}{|c|c|c|c|c|c|c|c|c|}
\hline \multirow[b]{2}{*}{ Delitos } & \multicolumn{2}{|c|}{1951} & \multicolumn{2}{|c|}{1953} & \multicolumn{2}{|c|}{1958} & \multicolumn{2}{|c|}{1960} \\
\hline & 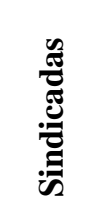 & 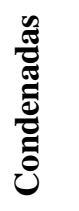 & : & ن & 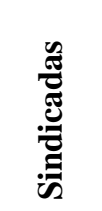 & 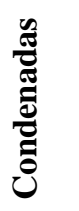 & 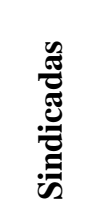 & نَّ \\
\hline Homicidios & 154 & 21 & 175 & 28 & 143 & 26 & 186 & 51 \\
\hline Asesinatos & 19 & 1 & 47 & 9 & 10 & 9 & 15 & 6 \\
\hline Infanticidios & 47 & & 92 & 8 & 78 & & 63 & \\
\hline Aborto & 1.705 & 1 & 72 & & & & & \\
\hline Lesiones personales & 14 & 378 & 2.215 & 228 & 3.269 & 218 & 3.412 & 236 \\
\hline Riñas & 21 & & & & & & 186 & NR \\
\hline $\begin{array}{l}\text { Corrupción de } \\
\text { menores }\end{array}$ & 11 & & 16 & & & & & \\
\hline $\begin{array}{l}\text { Abandono y expo. de } \\
\text { niños }\end{array}$ & 304 & 1 & 47 & & & & & \\
\hline Robo & 1.386 & 24 & 898 & 8 & 635 & 12 & 649 & 15 \\
\hline Hurto & 152 & 187 & 1.424 & 127 & 2.297 & 96 & 2.232 & 129 \\
\hline Estafa & 13 & 10 & 178 & 10 & 336 & 11 & 266 & 8 \\
\hline Secuestro & 49 & & 64 & & & & & \\
\hline $\begin{array}{l}\text { Inviolabilidad del } \\
\text { domicilio }\end{array}$ & 18 & & 72 & 1 & & & & \\
\hline Venta de drogas & 340 & & 22 & 2 & & & & \\
\hline Calumnia & 46 & 2 & 399 & & & & & \\
\hline Injuria & 6 & & 50 & 1 & & & & \\
\hline Incesto & 10 & & 9 & & & & & \\
\hline Fuga de presos & 10 & 4 & 25 & 8 & & & & \\
\hline Extorción y chantaje & 4 & & 7 & 2 & 9 & & 7 & \\
\hline $\begin{array}{l}\text { Proxenetismo y actos } \\
\text { homosexuales }\end{array}$ & 22 & & 24 & & & & & \\
\hline Otras defraudaciones & 92 & & 169 & 1 & & & 221 & 5 \\
\hline
\end{tabular}

Fuente: Anuario General de Estadística, Bogotá, DANE, 1951-1960 
De la tabla sobre delitos, podemos resaltar las lesiones personales como principal situación con un alto índice porcentual entre mujeres que fueron sindicadas y condenadas y deja las puertas abiertas para indagar por las relaciones familiares y sociales en los diferentes espacios cotidianos. Se trata de indagar por la vida precaria, las comodidades y los conflictos que tuvieron diferentes mujeres que día a día se vieron involucradas en procesos de criminalidad. De lo que se trata es de ubicar los lugares y los espacios en donde se hizo presencia de disputas con ofensas verbales, riñas y golpes. Sumado a todo esto le seguiría el hurto el cual estaría asociado a los oficios y las actividades económicas a las que estaban relacionadas muchas mujeres sindicadas y condenadas.

La lista de delitos documentada en el Anuario Estadístico hizo de su enunciación un formato en el cual se expuso una representación de la realidad existente haciendo de la coyuntura un hecho que amenazaba la disciplina y el control. Por otro lado, la sanción a la que se veían sometidos los acusados, ésta estuvo mediada por un proceso que no presentaba distinciones de género. Su aplicación se basó en el castigo a la norma moral-jurídica remitidos a un proceso de acusación o denuncia frente a un representante de la administración legal, el cual apelaba ante la sindicada una amonestación, retención, multa o condena, dependiendo de la infracción cometida. Hasta el momento se puede observar una muestra de lo que en su momento fue una construcción de un discurso que nos remite a la elaboración de imágenes la cual termina expresando una mirada del mundo a través de la población criminal y su control social.

Si la cuestión clave, en la mayoría de los Anuarios Estadísticos, consistía en exponer unas experiencias, también se elaboró una imagen de la criminalidad que causó intranquilidad al ser representada en la prensa como una situación socialmente dependiente de un administración encargada de su control. Aunque no se pueden conocer los detalles de vida de las personas que cometieron delitos, es importante interrogar las estadísticas y preguntarle ¿en qué contexto aparece el crimen?, esto con la finalidad de poder acercarnos al motivo de la representación.

\subsection{Región Caribe colombiana}

Es importante entender esta mirada nacional como el conjunto de información reconstruida por cada departamento, de aquí viene el interés por reconstruir el crimen desde un entorno regional el cual nos remite al Caribe colombiano. Los territorios que abarcan la región son el Departamento del Atlántico, el Departamento de Bolívar, el Departamento de Córdoba y el Departamento del Magdalena, los cuales contribuyeron desde sus ubicaciones en la elaboración del informe dentro del marco general del país. Dando una historia plural que no se diferencia en muchos aspectos del resto de las regiones pero que aun así refuerza la idea de una región que posee su propia realidad y necesidad. 
En síntesis, tenemos que en la década del cincuenta el Departamento del Atlántico registra una tasa de crimen del 0,04 mayor que el resto de los departamentos, esto se podría deber a su posición como una de las cuatro ciudades del país con mayor crecimiento poblacional, dinámica que se reflejó estos índices señalados.

En relación al Departamento de Bolívar se encontró un porcentaje de 0,02 y los departamentos restantes, se encuentran con un registro más bajo, como el caso del Departamento de Córdoba con 0,01 y el Departamento del Magdalena con 0,01. Es decir, que en la década de 1950 Bolívar se ubicó en un médium de criminalidad en relación a la región Caribe colombiana.

La siguiente tabla recoge los señalamientos que se han hecho:

Tabla 3: Número de sindicados en los sumarios iniciados en los departamentos de la región Caribe ${ }^{21}$

\begin{tabular}{|c|c|c|c|c|c|c|}
\hline \multirow{2}{*}{ Año } & \multicolumn{2}{|c|}{ Sumarios en el País } & \multicolumn{2}{|c|}{ Atlántico } & \multicolumn{2}{|c|}{ Bolívar } \\
\hline & Hombres & Mujeres & Hombres & Mujeres & Hombres & Mujeres \\
\hline 1940 & 37.341 & 4.307 & $\begin{array}{r}604 \\
(1.6 \%)\end{array}$ & $\begin{array}{r}59 \\
(1.3 \%)\end{array}$ & $\begin{array}{r}990 \\
(2.6 \%)\end{array}$ & $\begin{array}{r}79 \\
(1.8 \%)\end{array}$ \\
\hline 1950 & 60.559 & 5.520 & $\begin{array}{r}2.519 \\
(4.1 \%)\end{array}$ & $\begin{array}{r}294 \\
(5.3 \%)\end{array}$ & $\begin{array}{r}.216 \\
(2.0 \%)\end{array}$ & $\begin{array}{r}58 \\
(1.0 \%)\end{array}$ \\
\hline 1960 & 138 & 9.648 & $\begin{array}{r}3.781 \\
(2.7 \%)\end{array}$ & $\begin{array}{r}369 \\
(3.8 \%)\end{array}$ & $\begin{array}{r}2.594 \\
(1.8 \%)\end{array}$ & $\begin{array}{r}181 \\
(0.1 \%)\end{array}$ \\
\hline \multirow{2}{*}{ Año } & \multicolumn{2}{|c|}{ Sumarios en el País } & \multicolumn{2}{|c|}{ Córdoba ${ }^{22}$} & \multicolumn{2}{|c|}{ Magdalena } \\
\hline & Hombres & Mujeres & Hombres & Mujeres & Hombres & Mujeres \\
\hline 1940 & 37.341 & 4.307 & & & $\begin{array}{r}49 \\
(1.1 \%)\end{array}$ & $\begin{array}{r}49 \\
(0.8 \%)\end{array}$ \\
\hline 1950 & 60.559 & 5.520 & $\begin{array}{r}15 \\
(0.2 \%)\end{array}$ & $\begin{array}{r}15 \\
(0.2 \%)\end{array}$ & $\begin{array}{r}842 \\
(2.2 \%)\end{array}$ & $\begin{array}{r}926 \\
(1.5 \%)\end{array}$ \\
\hline 1960 & 138.208 & 9.648 & $\begin{array}{r}92 \\
(0.9 \%)\end{array}$ & $\begin{array}{r}92 \\
(0.9 \%)\end{array}$ & $\begin{array}{r}92 \\
(0.9 \%)\end{array}$ & $\begin{array}{r}92 \\
(0.9 \%)\end{array}$ \\
\hline
\end{tabular}

Fuente: Anuario General de Estadística, Bogotá, DANE, 1940-1960

Las estadísticas en 1940 hasta 1960 recuperaban y exponían, de forma minuciosamente categorizada y enumerada, las experiencias del crimen en las distintas regiones para poder consolidar un panorama general en Colombia. Aquellas cifras discutían, de manera implícita, demandas sociales y legales que fueron representadas y difundidas en la prensa como inseguridades o temores a los que se debían poner atención. Las estadísticas construyeron y justificaron la construcción de unas políticas públicas que pudieran restauran el orden social y moral que se vivía en el momento. Las estadísticas, también pudieron ser un documento que proporcionó unas herramientas metodológicas de reconstrucción útil para el conocimiento sobre la criminalidad y pudo ser una guía de precisión y verdad.

${ }^{21}$ Anuario General de Estadística, Bogotá, Departamento Administrativo Nacional de Estadística, 1950.

${ }^{22}$ Córdoba fue constituido Departamento en el año de 1952, por esta razón los datos que aparecen son de 1952. Para mayor ampliación véase: Anuario General de Estadística, Bogotá: Departamento Administrativo Nacional de Estadística, 19501951 


\section{Los delitos en el Departamento de Bolívar}

Junto al interés de mostrar, exponer y construir una imagen del crimen nacional, se dieron simultáneamente una serie de descripciones sobre los departamentos que conforman el país, lo cual nos permite ver características particulares del territorio geográfico, aspectos sociales y económicos, que contribuirán a la formación de representaciones sobre la población criminal. Todas estas compilaciones de datos permiten comprender una representación de las experiencias cuantificadas en un momento y coyuntura especifica.

Tenemos en este punto una mirada más local de las contravenciones que fueron abordadas desde el Departamento de Bolívar cuya capital es Cartagena. Localidad que no se encontró alejada de la realidad criminal expuesta anteriormente y podemos seguir notando una clara diferenciación marcada por hombres y mujeres en relación a la delincuencia. En el siguiente registro gráfico se mostrarán los números de personas sindicadas y cuantificadas por sus experiencias en comportamientos criminales.

Tabla 3: Número de sindicados en los sumarios iniciados en el departamento

\begin{tabular}{|r|r|r|r|}
\hline Años & \multicolumn{1}{|c|}{ Sumarios } & Hombres & \multicolumn{2}{c|}{ Mujeres } \\
\hline \multicolumn{3}{|c|}{ Sumarios iniciados en el Departamento de Bolívar } \\
\hline 1940 & 1.069 & 990 & 79 \\
\hline 1951 & 1.274 & 1.216 & 58 \\
\hline 1960 & 2.775 & 2.594 & 181 \\
\hline
\end{tabular}

Fuente: Anuario General de Estadística, Bogotá, DANE, 1940-1960.

Además, la tabla muestra cómo el registrar en números la criminalidad pudo significar un método del que se podía demostrar, por medio de información estadística, información apreciable sobre las conductas irruptoras a nivel local o del Departamento de Bolívar. En la reconstrucción de datos y la elaboración de dicho documento pueden estar separados del contexto y la lucha por la violencia que se vive a nivel nacional los cuales generaron inseguridad y Bolívar no fue la excepción.

Por otra parte, los problemas de desarrollo que está enfrentando el territorio en los cuales se destacan las situaciones de analfabetismo, la pobreza al no contar con espacios suficientes para el desarrollo económico y la migración interna $^{23}$ que a su vez estuvo mediada por el papel estratégico que jugó la región Caribe como uno de los puertos principales de comunicaciones con el extranjero.

El crimen representó inseguridad e irregularidad (masculina como femenina) y dicha preocupación generó cuestionamientos sobre las conductas de personas que fueron observadas y controladas como irruptoras. Es así como la estadística resaltó, por medio de números, contrastes morales vinculados al

${ }^{23}$ Dentro de los pasos básicos de estudio sobre la criminalidad en Colombia, se cita aspectos como los mencionados. Véase: Luis Vidales, "Un ensayo sobre criminalidad en el país", en: Historia de la estadística en Colombia, Bogotá: Banco de la Republica/Departamento Administrativo Nacional de Estadística, 1978- 194. 
disciplinamiento asociados al estado civil lo oficios, la educación, la sexualidad hechos considerados como trascendentes y que deben conocerse para su intervención. De este modo quienes creaban las estadísticas mostraron su visión de la "realidad" y sus argumentos sobre lo que determinaba una experiencia criminal tal y como lo veremos en la siguiente gráfica:

Gráfico 1: Sindicados en el Departamento de Bolívar década de 1950

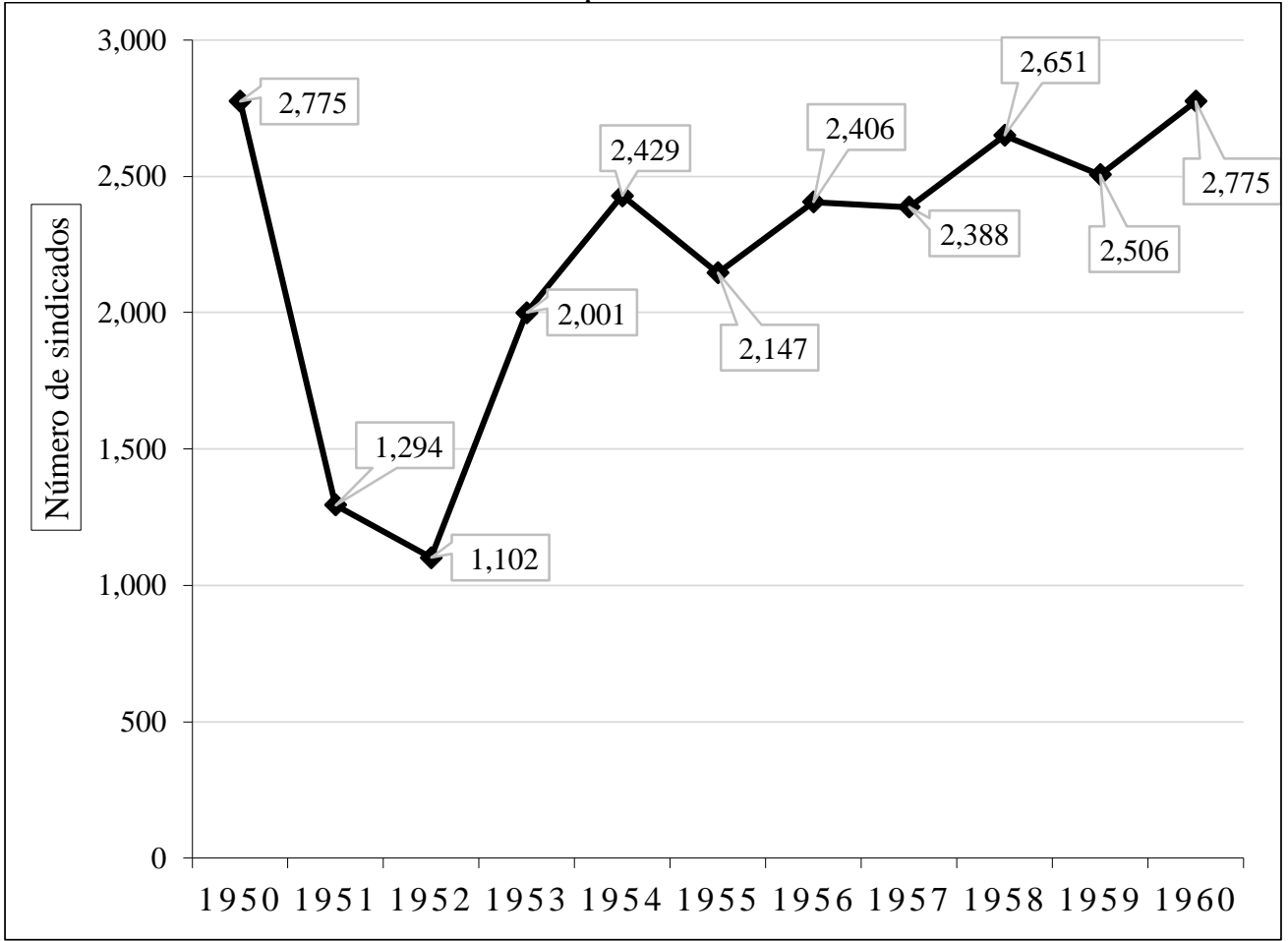

Fuente: Anuario General de Estadística, Bogotá, DANE, 1950

La gráfica es un conjunto de información numérica en el que se exponen experiencias que no fueron ajenas a mujeres ni a hombres. La información graficada invita a categorizar una combinación social en el cual existe un predominio de hombres sobre las mujeres sindicadas quienes no superaron el $10 \%$. Los anteriores puntos porcentuales, permiten apuntar una criminalidad por parte de los hombres que aumentó un 3,7 mientras que en las mujeres hubo un crecimiento del 2,2, expresando un relativo acercamiento que puede dar cuenta de cambios de conductas y pautas de comportamiento social entre uno y otro.

Los porcentajes señalados anteriormente, más que verdades, se aproximaron a lo que se mostró en la prensa ante una sociedad que se cuestiona por lo sucedido y por conocer sobre lo que pasaba. Si comparamos dichos resultados con los datos estadísticos del censo, puede ser visto como un hecho histórico, en otras palabras, son representaciones y datos reales de una situación acontecida. 
Grafico 2: Hombres y Mujeres sindicados en el Departamento de Bolívar en la década de 1950

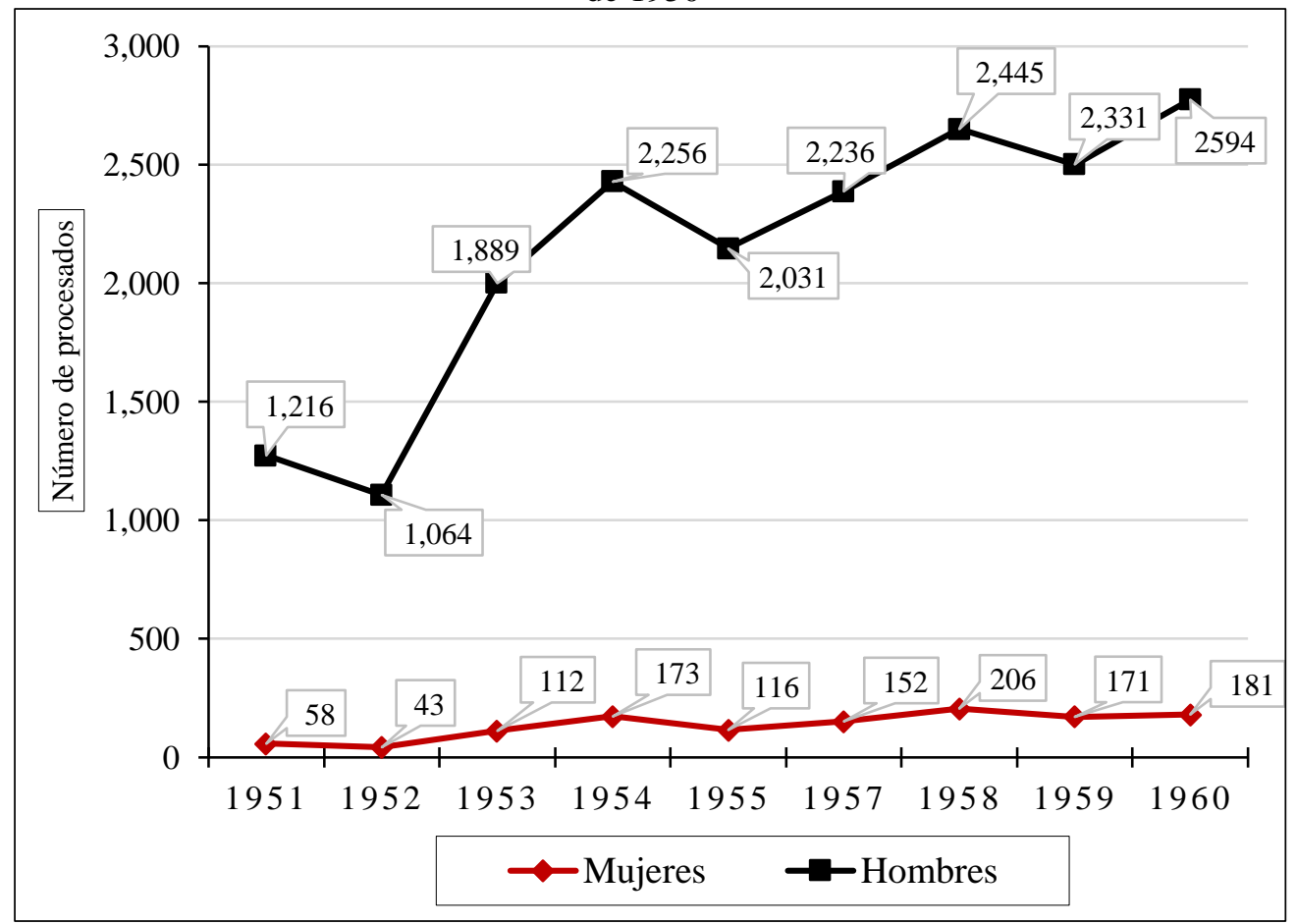

Fuente: Anuario General de Estadística, Bogotá, DANE, 1950

Las tendencias señaladas, no son más que la representación de un contexto, en donde, unos cuerpos fueron regulados por medios políticos y legales en los que se configuró una historia que está mediada por relaciones del pasado (motivos y consecuencias) y del presente (criminal o transgresor) de las personas estudiadas. Por otro lado, la división sexual que se realiza permite cuestionarnos por las vivencias de mujeres como de hombres los cuales están mediados por subjetividades distintas; en otras palabras, la muestra nos refleja el soporte de un sistema reglamentario con prohibiciones.

Las referencias de criminalidad y su división sexual para el departamento, no son más que una construcción histórica y cultural la cual está basada en un proceso de simbolización en el que los "productores estadísticos" desarrollaron un sistema de referencias. Dichas tipologías no son más que la configuración de unos intereses de quien construye el documento y quien cuestiona dicha problemática. El resultado de esto es, una sociedad que busca interpretar ciertas construcciones simbólicas para compartir y debatir ciertos significados.

En este orden de ideas, encontramos en los discursos de la prensa que el Departamento de Bolívar se encuentra en un momento de gestión, dirigida a la transformación y el mejoramiento de sus condiciones ${ }^{24}$. La seguridad como

\footnotetext{
${ }^{24}$ Dentro de algunos problemas y cambios que enfrenta la ciudad para este periodo, se registraron secciones de quejas por parte de ciudadanos que piden solución a problemas y como dicen, son tantos los problemas que acogen que es imposible enumerarlos, pero entre ellos se destacan o son muy recurrentes el alcantarillado, las carreteras, agua potable, luz, energía
} 
discurso en la prensa apeló a factores de inseguridad social, que presentó opciones de alternativas para la vigilancia en los barrios, evitar el vandalismo, los robos en las casas domiciliarias, los atracos en las calles a confiados ciudadanos que transitan por determinados lugares de la ciudad. Esta problemática, creó espacios de opinión donde se les permitió apelar a mayores factores de atención, horarios de vigilancia e inspecciones de policía que brinden mayor cuidado personal de la sociedad ${ }^{25}$.

No obstante, la relación directa entre las distancias geográficas y su comunicación tal vez puede ser un factor de observación en este apartado, donde se encontró que, de un total de ocho departamentos que agrupan la región Caribe, sólo cuatro presentaron información en las tres décadas del cuarenta al sesenta, sin que esto dejara de plantear crecimiento en los registros de criminalidad. Sin duda los factores de desplazamientos de la población, son significativos para comprender los problemas sociales de la época como la inseguridad, robos, y hechos de sangre ${ }^{26}$.

\section{1. ¿Cuáles eran sus actividades o profesiones económicas?}

\section{Lucia Agames Arroyo denunciada por robo [...] fue contratada para que hiciera el aseo del Bar "Embajador", hasta cuando se le ocurrió sustraerse algunos artículos que se halló al alcance de la mano. \\ Cargó con dos vestidos de seda de color azul con rojo, una falda de paño color azul, dos cadenas de oro con sus respectivas medallas y una sortija de oro, todos de propiedad de la esposa del dueño ${ }^{27}$.}

Las mujeres estudiadas en este apartado corresponden a unas características muy marcadas por sus actividades socioeconómicas. Para este trabajo analizaremos las actividades de mujeres muy ligados a su condición de clase. Investigaciones relacionadas a este tema han mostrado que, las mujeres pertenecientes a la clase alta se dedicaban a actividades de cuidado y en algunas excepciones se ocupaban de los negocios, mientras que las mujeres de la clase media, éstas pudieron incursionar en profesiones formales (maestras, enfermeras, secretarias). Y por último, las mujeres de bajas condiciones, su trabajo estaba supeditado a la necesidad y relacionado con los mismos oficios que realizaban en casa $^{28}$, otras robaron o estafaron.

\footnotetext{
y electricidad, la higiene y salubridad pública, carreteras, escuelas, tierras para agricultores, etc., etc. véase: "La nación y el alcantarillado", El Universal, Cartagena, jul. 16 1959. "Problemas Bolivarenses" El Universal, Cartagena ene. $21,1959$. "Planes para Bolívar", El Universal [Cartagena], sep. 1, 1959

25 "Factores de la inseguridad", El Universal [Cartagena], sep. 1, 1959

${ }^{26}$ Gloria Bonilla Veléz, , "Representaciones de la mujer en el mundo público: prostitución y delincuencia", en Las mujeres en la prensa de Cartagena de Indias 1900 - 1930, Cartagena, Editorial Universitaria, 2011, pp. 225-304. Saydi Nuñez Cetina, “¿Víctimas o Victimarias? Mujeres delincuentes en Bogotá 1950-1960”, en Patricia Tovar (ed.), Familia, Género y Antropología, Desafíos y Transformaciones, de, 198-247, Bogotá, Instituto Colombiano de Antropología e Historia, 2003

27 "Fue Capturada la mujer que robó en el Bar "Embajador", El Universal, viernes 15 de abril de 1955.

${ }^{28}$ Ivonne Urriola Pérez, "Espacio, oficio y delitos femeninos: el sector popular de Santiago. 1900-1925", Historia, 32, 1999: 459. Gloria Estela Bonilla Vélez, "Representaciones sociales de la mujer en el espacio público: mujer, trabajo y economía" en Representaciones de las mujeres en la prensa de Cartagena de Indias, p. 181.
} 
De acuerdo con los datos proporcionados por Gloria Bonilla Vélez, la prensa hace unas representaciones de algunas mujeres cartageneras como proveedoras principales o co-proveedora del sostenimiento familiar, el cual se tornó visible ${ }^{29}$. Explica cómo en esa época, las mujeres jefas de hogar podían ser solteras, viudas o separadas. Pero a su vez, este estudio muestra cómo se destacan en el sector informal y lo visibilizó como un tema problemático al ver el trabajo de las mujeres como una transgresión a su asignación al mundo de lo doméstico. Bajo esta lógica, encontramos diferentes actividades publicaciones que muestran una relación entre los oficios desempeñados y actividades prohibidas. ${ }^{30}$

En esta dinámica, tenemos algunas noticias de prensa que hablan de la aparición de las actividades económicas de las sindicadas asociadas en trabajos domésticos. Este fue un oficio que les permitió sustraer artículos pequeños como joyas, aros o prendedores. También se vieron acusadas de robar vestidos, o dinero lo que podría responder a posibles deudas o deterioro sufrido por sus condiciones de vida.

Para el caso del censo, las que se encontraban ahí detalladas fueron inscritas con actividad profesional relacionadas al sector de los servicios, quehaceres de la casa o haciendas y mujeres públicas. Acciones que pueden ser consideradas y desempeñadas como propias de las mujeres de los sectores populares y de zonas rurales. ${ }^{31}$

Tabla 4: Actividades y profesiones económicas de las sindicadas ${ }^{32}$

\begin{tabular}{|l|c|c|c|c|c|c|}
\hline \multirow{2}{*}{$\begin{array}{l}\text { Actividades y } \\
\text { profesiones }\end{array}$} & \multicolumn{2}{|c|}{1951} & \multicolumn{2}{c|}{1953} & \multicolumn{2}{c|}{1958} \\
\cline { 2 - 7 } & Sindicada & Condenada & Sindicada & Condenada & Sindicada & Condenada \\
\hline $\begin{array}{l}\text { Mujeres en } \\
\text { oficios } \\
\text { domésticos } \\
\text { (exclusive } \\
\text { sirvientas) }\end{array}$ & 21 & & 45 & & & \\
\hline $\begin{array}{l}\text { Quehaceres de } \\
\text { la casa, en } \\
\text { estancia o } \\
\text { haciendas }\end{array}$ & & & & & & \\
\hline $\begin{array}{l}\text { Mujeres } \\
\text { públicas }\end{array}$ & 3 & & 12 & & & \\
\hline
\end{tabular}

Fuente: Anuario General de Estadística, Bogotá, DANE, 1951-1958

La tabla, permite analizar la manera en como el Anuario Estadístico representó desde las actividades económicas características que definen a las mujeres a partir de los oficios relacionados con su sexo. Nos permite ver cuáles eran las posibilidades vitales y las oportunidades reducidas a las que

\footnotetext{
${ }^{29}$ Gloria Estela Bonilla, "Representaciones sociales de la mujer en el espacio público: mujer, trabajo y economía”, p. 183

${ }^{30}$ G. Bonilla Veléz, "Representaciones de la mujer en el mundo público: prostitución y delincuencia" pp. 225-304

${ }^{31} \mathrm{Se}$ considera así al ser una actividad desempeñada por mujeres de bajos recursos, bajos niveles educativos el cual le permitirá ingresar a un trabajo formal.

${ }^{32}$ Encontramos que para este apartado el censo no hace una división por sexo, pero deja claro con estas tres categorías cuales son los lugares más comunes de las mujeres sindicadas. En lo relacionado a los años de 1958 hasta 1960 el interés por clasificar los oficios cambia a una mirada por la clase de trabajo.
} 
estuvieron inmersas las mujeres sindicadas. La manera en como se vieron enfrentadas a situaciones criminales se refleja en su participación como "sirvientas" o como "mujeres publicas" 33 dos oficios determinantes a partir de su condición de género y en las que tuvieron que enfrentar diferentes situaciones y la criminalidad es una de ellas. Son dos aspectos en los que tocaría seguir indagando, pues las estadísticas para los periodos estudiados son muy escasos y presenta muy poca información.

La estadísticas reflejadas en la tabla, lo que nos muestra son procesos judiciales que nos hacen cuestionar la participación de mujeres populares y su relación con la justicia. Dejan las puertas abiertas para seguir indagando por la participación de "sirvientas", "lavanderas", "prostitutas", entre otras, que fueron visitantes de los juzgados por diferentes situaciones. No obstante, tocaría seguir indagando por la asistencia a los juzgados de forma voluntaria para solicitar ayuda y por este motivo se vieron involucradas en los procesos.

\section{Consideraciones finales}

La exploración del Anuario Estadístico y su registró o representación del país, las regiones y los departamentos que mostraron unas repercusiones en los comportamientos, del cual se hizo mayor énfasis en las mujeres, no es más que una propuesta general y un acercamiento a las diferentes formas de representar la criminalidad. Se trata de realizar una lectura de las estadísticas que son datos numéricos que nos permiten observar un suceso o acontecimientos de manera global y resumida. A partir de las estadísticas, se pudo ver una composición normativa del contenido relacionado con la Criminalidad y Justicia en donde podemos encontrar unas diferenciaciones y semejanzas de género en la cual se reproducen códigos, leyes y mandatos en formato de graficas para el funcionamiento adecuado de unas normas.

Las estadísticas de Criminalidad y Justicia son vivencias personales y colectivas que obedecen a un incumplimiento de o resistencia de unas estructuras sociales que no siempre permiten el cumplimiento de los "deberes, obligaciones y prohibiciones asignadas a los géneros y marcan las formas de relación entre éstos, sus límites y su sentido". ${ }^{34}$ De lo que se trata entonces es de ubicar a mujeres y hombres en la construcción de unos acontecimientos que están enmarcados en un contexto histórico y se pueden identificar formar de ser representados en un mundo que busca dar sentido a determinadas situaciones. Así, al presentarnos una división sexual del crimen nos están

\footnotetext{
${ }^{33}$ Trabajos que han permitido hacer visible una historiografía sobre la prostitución en Cartagena de Indias se puede encontrar en: Elsy Sierra Guerrero, "La prostitución en Cartagena. Higiene física e higiene moral 1915-1980", trabajo de grado para optar al título de Historiadora, Universidad de Cartagena, 1998; Juan Manuel Ortiz Martínez y Jorge Orozco Padilla, " DDudosa ortografía', cuerpos antihigiénicos y espacios insalubres: prostitución e higiene pública en Cartagena 1880-1920” Unicarta 108, 2010: 8-17; Alberto Taborda Mercado y Never Barrios Herrera. "Entre la puta y la muralla: La representación social de la prostitución femenina en Cartagena entre 1940-1950", Cuadernos de Literatura del Caribe e Hispanoamérica 11, 2010: 155-171; Raúl Cera Ochoa, "Mujeres frente a la incidencia de la pobreza e insalubridad pública en Cartagena (Colombia), 1915-1928", Historelo. Revista de Historia Regional y Local 15, (8), 2016: 202-237

${ }^{34}$ Marcela Lagarde, "El género", fragmento literal: 'La perspectiva de género', en Género y feminismo. Desarrollo humano $y$ democracia, Madrid, Ed. horas y HORAS, 1996, p. 15
} 
describiendo unas formas de organizar la vida social a partir de la interacción de consensos institucionales resumidos en este documento.

La presentación y organización de unas estadísticas dejan las puertas abiertas para dialogar con otros documentos que crucen la información presentada en las estadísticas con las representaciones en la prensa, los archivos judiciales, los informes de policía, entre otros. También, se podría ver como en la información recolectada se pudo revelar un perfil un poco difuso pero muy general de los personajes que nos interesa y de manera amplia se pudo indagar en los delitos más comunes o las experiencias que situaron a las mujeres en contextos criminales. Por ultimo, se pudo hacer una reconstrucción general que parte de Colombia seguido de la región Caribe para llegar al Departamento de Bolívar en donde la información cada vez se hacia menos accesible y la información se iba reduciendo es por este motivo que las puertas quedan abiertas para seguir indagando.

Se trata de hacer una historia cultural del crimen y por eso se indagan en las representaciones estadísticas para reconstruir procesos judiciales en los que muchas mujeres fueron protagonistas. Esta propuesta, deja las puertas abiertas para seguir indagando en las representaciones estadísticas y, sobre todo, seguir buscando otras formas en las que el crimen fue representado.

\section{Bibliografía}

\section{Fuentes Primarias}

Departamento Administrativo Nacional de Encuestas (DANE), Anuario Estadístico, Censos de 1951, Bogotá, 1951.

Archivo Periódico El Universal de Cartagena, 1950 - 1960.

\section{Fuentes documentales}

Asociación Colombiana para Estudio de la Población (ACEP), La Población de Colombia, Bogotá, C.I.C.R.E.D, 1974.

Bonilla Vélez, Gloria Estela, "Representaciones sociales de la mujer en el espacio público: mujer, trabajo y economía", en Representaciones de las mujeres en la prensa de Cartagena de Indias 1900-1930, Cartagena: Editorial Universitaria, 2011, pp. 148221

Bonilla Vélez, Gloria Estela, "Representaciones de la mujer en el mundo público: prostitución y delincuencia", en Representaciones de las mujeres en la prensa de Cartagena de Indias 1900-1930, Cartagena, Editorial Universitaria, 2011, pp. 148221.

Bushnell, David, Colombia. Una nación a pesar de sí misma. De los tiempos precolombinos a nuestros días, Bogotá, Editorial Planeta, 1994.

Casas Orrego, Alvaro. Higienizar, medicar, gobernar. Historia, sociedad y salud en Colombia, Medellín, GIHSA, Universidad Nacional de Colombia sede Medellín, 2004. 
Castrillón Castro, Carlos Mario, López Bajo, Lizett Paola, "Al límite de la violencia de género: representaciones de transgresiones protagonizadas por mujeres en la prensa cartagenera, 1940-1950”. La Manzana de la Discordia, 11, (1), 2016: 29-39

Cera Ochoa, Raúl Antonio. "Mujeres frente a la incidencia de la pobreza e insalubridad pública en Cartagena (Colombia), 1915-1928." Historelo. Revista de Historia Regional y Local 8, (15), 2016: 202-237.

Estrada Orrego, Victoria, “¿Cuántos somos? Una historia de los censos civiles y de la organización estadística en Colombia en la primera mitad del siglo XX". Historia Critica, 64, 2017: 141-160.

Foucault, Michel, Vigilar y castigar: nacimiento de la prisión, Madrid: Siglo XXI, 1994. García Amézquita, July, “Monjas, presas y 'sirvientas': la cárcel de mujeres del Buen Pastor, una aproximación a la historia de la política criminal y del encierro penitenciario femenino en Colombia. 1890-1929" Bogotá, Tesis de Maestría, Universidad Nacional de Colombia, 2010.

Lagarde Marcela, "El género", fragmento literal: 'La perspectiva de género", en Género y feminismo. Desarrollo humano y democracia, Madrid, Ed. horas y HORAS, 1996, pp. 13-38.

Mélich, Joan-Carles, El otro de sí mismo. Por una ética desde el cuerpo, Barcelona, Editorial UOC, 2010, pp. 86

Nuñez, Cetina Saydi. “¿Víctimas o Victimarias? Mujeres delincuentes en Bogotá 1950 1960”, en Patricia Tovar (ed.), Familia, Género y Antropología, Desafíos y Transformaciones, Bogotá, Instituto Colombiano de Antropología e Historia, 2003, pp. 198-247

Ortiz Martínez, Juan Manuel, y Orozco Padilla, Jorge Armando, “'Dudosa ortografía', cuerpos antihigiénicos y espacios insalubres: prostitución e higiene pública en Cartagena 1880-1920". Unicarta 108, 2010: 8-17.

Patiño Millán, Beatriz, "Las mujeres y el crimen en la época colonial", en Las mujeres en la historia de Colombia, Bogotá, Norma, 1995, pp. 77-117.

Scott, Joan W., "El género: una categoría útil para el análisis histórico", en J. Amelang, \& M. Nash (eds.), Historia y género: las mujeres en la Europa moderna y contemporánea, Madrid, Edícions Alfons el Magnanim, 1990, pp. 23-58.

Scott, Joan W., "Experiencia”. Revista La Ventana, 2001, pp. $42-73$.

Scott, Joan W., "El mundo del trabajo a traves de las estadfsticas. La "Estadfstica de la industria en Paris ( 1847-1 848)", en Genero e Historia, México, Fondo de Cultura Economica/Universidad Autónoma de la Ciudad de México, 2008.

Taborda Mercado, Alberto, y Never Barrios, Herrera, "Entre la puta y la muralla: La representación social de la prostitución femenina en Cartagena entre 1940-1950." Cuadernos de Literatura del Caribe e Hispanoamérica, $\mathrm{n}^{\circ}$ 11, 2010, pp. 155-171 
Urriola Pérez, Ivonne, "Espacio, oficio y delitos femeninos: el sector popular de Santiago. 1900-1925". Historia, 32, 1999: 443-483

Vidales, Luis, Historia de la estadística en Colombia, Bogotá, Banco de la Republica/Departamento Administrativo Nacional de Estadística, 1978. 